\title{
Assessment of gynecological and lifestyle-related risk factors of ovarian cancer
}

\author{
Gazala Abdulaziz ${ }^{1 *}$, Natalia Anna Welc ${ }^{1 *}$, Emilia Gąsiorowska², Ewa Nowak-Markwitz² \\ ${ }^{1}$ Student of the Poznań University of Medical Sciences, Poznan, Poland \\ 2Department of Gynecology, Obstetrics and Gynecologic Oncology, Division of Gynecologic Oncology, Poznan University \\ of Medical Sciences, Poznan, Poland \\ *These authors contributed equally to this work.
}

\begin{abstract}
Introduction: Ovarian cancer remains the most lethal gynecological cancer. Assessment of gynecological and lifestyle-related risk factors is essential to reduce the occurrence and the mortality rate of the disease.

Material and methods: Surveys were collected among 71 patients with ovarian cancer and 76 women without gynecological cancer. Questionnaires included questions about medical history and lifestyle in the past.

Results: The control group had breastfed longer $(p=0.034)$ and used hormonal contraception more often $(p=0.00037)$ than the study group. The patients in FIGO (French. Fédération internationale de gynécologie et d'obstétrique) stage III or IV had a higher number of lifetime ovulatory cycles $(p=0.001)$ than the control group. Women at FIGO stage IV slept significantly less than patients at other stages $(p=0.0026)$. Oncological patients reporting sedentary work more often were diagnosed at advanced stages $(p=0.00328)$. The risk of ovarian cancer was 0.046 times smaller for women who had given birth $(p=0.025), 0.94$ times smaller for every one month longer breastfeeding $(p=0.0428), 0.677$ times smaller for every one year older age at menarche ( $p=0.0152), 0.106$ times smaller for women who had used hormonal contraception $(p=0.0019)$, and 5.46 times higher for women who ever worked night shifts ( $p=0.0128)$.

Conclusions: Our study proves the importance of both gynecological and lifestyle-related risk factors of ovarian cancer and their impact on its prevalence. Lifestyle-related risk factors cannot be ignored, as they might have a direct influence on the aggravation of the risk of this type of cancer. Promoting an adequate amount of physical activity and sleep, breastfeeding, and having children could improve the detection and treatment of ovarian cancer in general.
\end{abstract}

Key words: ovarian cancer, risk factors, lifestyle, oral contraceptives, parity, breastfeeding

\section{Introduction}

Ovarian cancer remains the most lethal gynecological cancer. Due to the fact that there is no effective screening process available and the early symptoms are often non-distinctive, the diagnosis is usually made when cancer is advanced, at FIGO (French. Fédération internationale de gynécologie et d'obstétrique) stage III or IV, which results in a low survival rate. According to the Polish National Cancer Registry, ovarian cancer is the $4^{\text {th }}$ leading cause of death from malignancies among women in Poland, following lung, breast, and colon cancer. Between 2010 and 2018, it caused 23,724 deaths [1]. High-grade serous carcinoma is the most commonly diagnosed form of ovarian cancer; however, other histological types include clear cell, endometrioid, mucinous, undifferentiated, and transitional cell tumor.

The pathogenesis of ovarian cancer remains unclear; however, many theories have been proposed. Fathall's theory on incessant ovulation explains the negative impact of ovulations on the ovaries due to the rupture of the ovarian surface epithelium, which may promote mutations [2]. Another theory focuses on the constant inflammation of the ovaries due to their intraperitoneal location and the inflammatory character of the ovulation itself [3]. Based on these theories, several risk factors have been assessed. These include early menarche, late menopause, nulliparity, and lack of breastfeeding, which increase the number of lifetime ovulatory cycles (LOC). Genetic mutations such as BRCA1 and BRCA2 mutation, Lynch syndrome, and PeutzJeghers syndrome increase the risk as well [4].

The aim of the study was to identify new and assess already known risk factors of ovarian cancer among the Polish population as it is crucial to reduce the occurrence and the mortality of the disease.

\section{Material and methods}

Between February 2020 and July 2021, 71 women with the diagnosis of ovarian cancer and 76 women 
without gynecological cancer were recruited to the study and control group respectively (Table 1). Women were informed that the survey was anonymous and it was collected after receiving consent. Both groups received the same questionnaires. The control group's surveys were collected among women with vaginal prolapse or uterine fibroids. All women were interviewed at the Department of Gynecology, Obstetrics and Gynecologic Oncology at Poznan University of Medical Sciences.

The questionnaires included questions about medical history (e.g. body mass index - BMI, menarche, menopause, number of pregnancies and births, total duration of breastfeeding, the use of hormonal contraception or intrauterine device and the duration of therapy, chronic diseases, vaginal infections, blood type) and lifestyle, including profession, type of work (sedentary or standing), shifts at night, the amount of physical activity per week, average sleep duration, sleeping disorders, and the usage of painkillers. The data concerning the levels of CA125 and HE4 markers at the diagnosis, as well as FIGO stages (Table 2) and histological types of carcinomas (Table 3), were also collected.

Statistical analysis was performed using the Microsoft Excel program and the R language. Data obtained from the study group were compared with the control group. We performed the independent t-test and the test of proportions. The relationship between the potential risk factors and the risk of ovarian cancer was estimated by logistic regression. Odds ratios (ORs) and corresponding 95\% confidence intervals $(\mathrm{Cl})$ were calculated (Table 4). The significance level of these tests was set at less than 0.05 .

\section{Results}

The mean age of the study group was $61.0 \pm 10.6$ years and the mean age of the control group was $59.7 \pm 12.7$ years. The mean height of women in the study group was $1.61 \mathrm{~m}$, in comparison to $1.63 \mathrm{~m}$ in the control group ( $p=0.032$ ). The mean $\mathrm{BMI}$ value of the study group was 26.2 and 27.4 in the control group ( $p=0.114$ ). $18.3 \%$ of women in the study group and $27.6 \%$ of the control group were obese (BMI > 30).

$97.4 \%$ of women in the control group had given birth, in comparison to $87.3 \%$ of the women in the study group. The statistical significance of this result was confirmed in the proportion test performed in the $\mathrm{R}$ language $(p=0.045)$. The logistic regression analysis showed that the odds of having cancer for women who had given birth are 0.046 times smaller $(O R=0.046$; $95 \% \mathrm{Cl}: 0.002-0.523 ; p=0.025)$ than for women who had not given birth, holding all other variables constant.

The mean duration of breastfeeding among the control group was higher (14 months) than among the patients diagnosed with ovarian cancer (8 months). The difference was statistically significant both be-
Table 1. Characteristics of the study group and the control group

\begin{tabular}{lcc}
\hline Variable & Study group & Control group \\
\hline Number of patients recruited & 71 & 76 \\
\hline Average age (years) & $61.0 \pm 10.6$ & $59.7 \pm 12.7$ \\
\hline Average height $(\mathrm{m})$ & $1.61 \pm 0.10$ & $1.63 \pm 0.10$ \\
\hline Average weight $(\mathrm{kg})$ & $67.8 \pm 11.2$ & $72.9 \pm 14.4$ \\
\hline Average BMI & $26.2 \pm 4.1$ & $27.4 \pm 5$ \\
\hline $\begin{array}{l}\text { Average age at diagnosis } \\
\text { (years) }\end{array}$ & $58.6 \pm 10.8$ & - \\
\hline $\begin{array}{l}\text { CA125 value above normal } \\
\text { at diagnosis (\%) }\end{array}$ & 73.2 & - \\
\hline $\begin{array}{l}\text { HE4 value above normal } \\
\text { at diagnosis (\%) }\end{array}$ & 54.9 & - \\
\hline
\end{tabular}

$\mathrm{BMI}$ - body mass index

Table 2. Distribution of FIGO stages among patients recruited to the study group

\begin{tabular}{lcc}
\hline FIGO stage & $\boldsymbol{n}$ & $\boldsymbol{\%}$ \\
\hline I & 11 & 15.5 \\
\hline II & 3 & 4.2 \\
\hline III & 44 & 62.0 \\
\hline IV & 13 & 18.3 \\
\hline FIGO - French. Fédération internationale de gynécologie et d'obstétrique
\end{tabular}

Table 3. Distribution of histopathological types of ovarian cancer and FIGO stages among patients recruited to the study group

\begin{tabular}{lcc}
\hline Histopathological type & $\boldsymbol{n}$ & $\mathbf{\%}$ \\
\hline Serous carcinoma & 66 & 93 \\
\hline Clear-cell carcinoma & 2 & 2.8 \\
\hline Endometrioid carcinoma & 3 & 4.2 \\
\hline FIGO - French. Fédération internationale de gynécologie et d'obstétrique
\end{tabular}

Table 4. Assessment of odds ratios of particular risk factors in comparison to the control group

\begin{tabular}{lcc}
\hline Variable & $\begin{array}{c}\text { Odds ratio } \\
(95 \% \mathrm{Cl})\end{array}$ & $p$-value \\
\hline Menarche (years) & $0.677(0.49-0.92)$ & $p=0.0152$ \\
\hline Giving birth & $0.046(0.002-0.523)$ & $p=0.025$ \\
\hline Breastfeeding (months) & $0.94(0.87-0.99)$ & $p=0.0428$ \\
\hline $\begin{array}{l}\text { Using hormonal } \\
\text { contraception }\end{array}$ & $0.106(0.02-0.41)$ & $p=1.9 \times 10^{-3}$ \\
\hline Ever working night shifts & $5.46(1.52-22.62)$ & $p=0.0128$ \\
\hline
\end{tabular}

tween the control and the study group ( $p=0.034)$ and between the control group and the patients with advanced cancer (FIGO stages III and IV; $p=0.049$ ). Also, among women who had not breastfed at all, more often there were patients with FIGO stage III or IV than patients with FIGO stage I or II $(p=0.002)$. The odds of having cancer were calculated as 0.94 times smaller for 
Table 5. Comparison of gynecological variables between the study group and the control group

\begin{tabular}{lccccc}
\hline Variable & $\begin{array}{c}\text { Average result } \\
\text { of the variable }\end{array}$ & $\begin{array}{c}\text { SD of the } \\
\text { result }\end{array}$ & $\begin{array}{c}\text { Average result } \\
\text { of the variable }\end{array}$ & $\begin{array}{c}\text { SD of the } \\
\text { result }\end{array}$ & $p$-value \\
\hline Age at the first delivery (years) & 23.3 & 4.4 & 23.9 & 3.6 & 0.36 \\
\hline Number of deliveries & 1.9 & 1.2 & 2.1 & 1.1 & 0.22 \\
\hline Duration of breastfeeding (months) & 8 & 9.3 & 14 & 19.1 & 0.034 \\
\hline Duration of hormonal contraception use (months) & 62 & 76.6 & 81 & 78.9 & $3.7 \times 10^{-4}$ \\
\hline Age at menarche (years) & 13.4 & 1.7 & 13.5 & 1.7 & 0.78 \\
\hline Age at menopause (years) & 48.5 & 6 & 49.6 & 4.8 & 0.27 \\
\hline Number of LOC & 426 & 84 & 396 & 105 & 0.055 \\
\hline
\end{tabular}

LOC - lifetime ovulatory cycles, SD - standard deviation

Table 6. Comparison of gynecological variables between the group of patients in FIGO stages III and IV and the control group

\begin{tabular}{|c|c|c|c|c|c|}
\hline \multirow[t]{2}{*}{ Variable } & \multicolumn{2}{|c|}{ Patients in FIGO stage III or IV } & \multicolumn{2}{|c|}{ Control group } & \multirow[t]{2}{*}{$p$-value } \\
\hline & $n$ & $\%$ & $n$ & $\%$ & \\
\hline Gave birth & 62 & 87.3 & 74 & 97.4 & 0.045 \\
\hline Gave birth once & 18 & 25.4 & 21 & 27.6 & 0.90 \\
\hline Breastfed & 41 & 71.9 & 56 & 73.7 & 0.05 \\
\hline Suffered from painful menstruation & 34 & 47.9 & 31 & 40.8 & $3.7 \times 10^{-5}$ \\
\hline Used hormonal contraception & 6 & 10.5 & 29 & 38.2 & $1.0 \times 10^{-3}$ \\
\hline Suffered from endometriosis & 5 & 7 & 8 & 10.5 & 0.65 \\
\hline Had a miscarriage & 11 & 15.5 & 12 & 15.8 & 1.0 \\
\hline Used intrauterine device & 6 & 8.5 & 11 & 14.5 & 0.38 \\
\hline $\begin{array}{l}\text { Reported having frequent or recurrent } \\
\text { vaginal infections }\end{array}$ & 17 & 23.9 & 13 & 17.1 & 0.41 \\
\hline
\end{tabular}

FIGO - French. Fédération internationale de gynécologie et d'obstétrique, SD - standard deviation

every one month increase in the duration of breastfeeding, holding all other variables constant $(\mathrm{OR}=0.94 ; 95 \%$ Cl: 0.87-0.99; $p=0.0428$ ).

The mean age at menarche was estimated at 13 years both in the study and control group. However, performing the logistic regression analysis allowed us to assume that for every one year increase in the age at menarche, developing ovarian cancer is 0.677 times less likely, holding all other variables constant $(\mathrm{OR}=0.67 ; 95 \% \mathrm{Cl}$ : 0.49-0.92; $p=0.0152$ ).

Among women in the study group who reported having painful menstruation throughout their life, more often there were patients with advanced cancer $\left(p=3.7 \times 10^{-5}\right)$.

$38.2 \%$ of women in the control group had used hormonal contraception, with the mean duration of the therapy being 81 months. Only $11.3 \%$ of patients with ovarian cancer took hormonal contraception, with the mean duration of the therapy estimated at 62 months. This outcome was statistically significantly different between these groups $\left(p=3.7 \times 10^{-4}\right)$, as well as between the control group and the patients with FIGO stages III and IV $\left(p=1.0 \times 10^{-3}\right)$. The odds for developing ovarian cancer for women who took hormonal contraception are 0.106 times smaller than for women who did not take hormonal contraception, holding all other variables constant $\left(\mathrm{OR}=0.106 ; 95 \% \mathrm{Cl}: 0.02-0.41 ; p=1.9 \times 10^{-3}\right)$. Out of all oncological patients who did not use hormonal contraception, those diagnosed in the third or fourth FIGO stage were more frequent $\left(p=3.024 \times 10^{-11}\right)$.

There was a statistically significant difference in LOC between the control group and the patients with advanced cancer (FIGO stages III and IV; $p=0.0304$ ) (Tables 5, 6).

$49.3 \%$ of women in the study group had blood type $A$, in comparison to $35.5 \%$ in the control group $(p=0.128)$. Among all patients with ovarian cancer who had blood type $A$, statistically significantly more often these were women diagnosed at FIGO stage III or IV $\left(p=1.7 \times 10^{-5}\right)($ Table 7$)$.

$39.5 \%$ of women in the study group reported having sedentary work (vs. 55.3\% in the control group, $p=0.08) .35 .1 \%$ of women with advanced cancer (at FIGO stage III and IV) reported having sedentary work, which is significantly less than in the case of the control group ( $p=0.03$ ). However, patients who had sedentary work more often had cancer at FIGO stage III or IV rather than at stage I or II $\left(p=3.3 \times 10^{-3}\right) .29 .6 \%$ of women in the study group performed physical activity regularly (at least 150 minutes of moderate-intensity activity per week), in comparison to $35.5 \%$ in the control group $(p=0.55)$. Women who did not exercise more often had 
Table 7. Comparison of the distribution of blood types between the study group, the control group, and the distribution of blood types in Polish society

\begin{tabular}{lcccccc}
\hline Blood type & \multicolumn{2}{c}{ Study group } & \multicolumn{2}{c}{ Control group } & p-value & \multirow{2}{*}{$\begin{array}{c}\text { Polish } \\
\text { society } \%\end{array}$} \\
\cline { 2 - 5 } & $n$ & $\%$ & 27 & 35.5 & 0.128 & 38 \\
\hline $\mathrm{A}$ & 35 & 49.3 & 16 & 21.1 & 0.667 & 17 \\
\hline $\mathrm{B}$ & 12 & 15.5 & 5 & 6.6 & 0.328 & 7 \\
\hline $\mathrm{AB}$ & 9 & 12.9 & 25 & 32.9 & 0.105 & 37 \\
\hline 0 & 14 & 19.7 & & & &
\end{tabular}

Table 8. Comparison of lifestyle-related variables between the study group and the control group

\begin{tabular}{|c|c|c|c|c|c|}
\hline \multirow[t]{2}{*}{ Variable } & \multicolumn{2}{|c|}{ Study group } & \multicolumn{2}{|c|}{ Control group } & \multirow[t]{2}{*}{$p$-value } \\
\hline & $n$ & $\%$ & $n$ & $\%$ & \\
\hline $\mathrm{BMI}>30$ & 13 & 18.3 & 21 & 27.6 & 0.25 \\
\hline Sedentary job & 28 & 39.4 & 42 & 55.3 & 0.08 \\
\hline Night shifts & 16 & 22.5 & 12 & 15.8 & 0.41 \\
\hline Regular exercise & 21 & 29.6 & 27 & 35.5 & 0.55 \\
\hline Sleeping problems & 20 & 28.2 & 32 & 42.1 & 0.11 \\
\hline \multirow[t]{2}{*}{ Analgesics usage } & 12 & 16.9 & 22 & 28.9 & 0.13 \\
\hline & $\begin{array}{l}\text { Average result } \\
\text { of the variable }\end{array}$ & $\begin{array}{l}\text { SD of the } \\
\text { result }\end{array}$ & $\begin{array}{l}\text { Average result } \\
\text { of the variable }\end{array}$ & $\begin{array}{l}\text { SD of the } \\
\text { result }\end{array}$ & $p$-value \\
\hline BMI & 26.2 & 4.1 & 27.4 & 5.0 & 0.11 \\
\hline Time seated at work per day (hours) & 7.1 & 1.1 & 6.8 & 1.4 & 0.45 \\
\hline Night shifts per week & 2.4 & 0.7 & 2.6 & 0.9 & 0.55 \\
\hline Time spent on physical activity per week (hours) & 1.7 & 2.8 & 2.1 & 3.9 & 0.521 \\
\hline Sleep duration (hours) & 6.8 & 1.4 & 7.1 & 1.1 & 0.128 \\
\hline
\end{tabular}

advanced cancer (at FIGO stage III or IV) than at stage I or II $\left(p=6.7 \times 10^{-8}\right)$.

$22.5 \%$ of patients in the study group reported having night shifts during their lifetime in comparison to $15.8 \%$ in the control group ( $p=0.406)$. The mean value of shifts per week was 2.5 in both control and study groups. Among women who reported ever working night shifts, more often these were women with FIGO stages III and IV $\left(p=1.0 \times 10^{-3}\right)$. Moreover, working night shifts was associated with a 5.46 times greater risk of cancer than for women who did not work night shifts, holding all other variables constant $(O R=5.46$; 95\% Cl: 1.52-22.62; $p=0.0128$ ).

The mean duration of sleep per day was 6.8 hours in the study group and 7.1 hours in the control group $(p=0.128)$. The median duration of sleep at FIGO stage IV was 5 hours, in comparison to 7 hours at FIGO stages I and III and 8 hours at FIGO stage II. Women with advanced cancer at FIGO stage IV slept significantly less than at other stages $\left(p=2.6 \times 10^{-3}\right) .28 .2 \%$ of women in the study group reported having sleeping disorders, whereas in the control group $42.1 \%$ of women reported having sleeping disorders $(p=0.111)$. Women with sleeping disorders more often had advanced cancer (at FIGO stage III or IV) than at stage I or II $\left(p=3.9 \times 10^{-5}\right)$.
Among interviewed women, $16.9 \%$ of the whole study group and $17.5 \%$ of women with advanced cancer at FIGO stages III and IV reported using painkillers every week (vs. $28.9 \%$ in the control group, $p=0.125$ ). However, women who did not use analgesics at all more often had cancer at FIGO stage III or IV than at stage I or II $\left(p=9.0 \times 10^{-10}\right)($ Tables 8-10).

\section{Discussion}

There have been many attempts at trying to determine what the exact risk factors of ovarian cancer are. One theory is that every ovulation causes damage to the epithelium of the ovary, subsequently leading to the healing process, during which genetic mutations can occur. Furthermore, each ovulation is accompanied by inflammation, being a source of oxidative stress. That is why it is acknowledged that women who have not given birth, breastfed or used hormonal contraception and also women who had their menarche early and menopause late are at significantly greater risk of developing ovarian cancer. The mentioned variables have a direct impact on LOC, which, when increased, might generate a higher risk of a cancerous process [2]. The results of our study confirmed this assumption and 
Table 9. Comparison of lifestyle-related variables between the group of patients in FIGO stages III and IV and the control group

\begin{tabular}{|c|c|c|c|c|c|}
\hline \multirow[t]{2}{*}{ Variable } & Patients in III & FIGO stage or IV & Control & group & \multirow[t]{2}{*}{$p$-value } \\
\hline & $n$ & $\%$ & $n$ & $\%$ & \\
\hline $\mathrm{BMI}>30$ & 11 & 19.3 & 21 & 27.6 & 0.36 \\
\hline Sedentary job (\%) & 20 & 35.1 & 42 & 55.3 & 0.03 \\
\hline Night shifts (\%) & 13 & 22.8 & 12 & 15.8 & 0.42 \\
\hline Regular exercise (\%) & 18 & 31.6 & 27 & 35.5 & 0.77 \\
\hline Sleeping problems (\%) & 17 & 29.8 & 32 & 42.1 & 0.21 \\
\hline \multirow[t]{2}{*}{ Analgesics usage (\%) } & 10 & 17.5 & 22 & 28.9 & 0.188 \\
\hline & $\begin{array}{l}\text { Average result } \\
\text { of the variable }\end{array}$ & $\begin{array}{l}\text { SD of the } \\
\text { result }\end{array}$ & $\begin{array}{l}\text { Average result } \\
\text { of the variable }\end{array}$ & $\begin{array}{l}\text { SD of the } \\
\text { result }\end{array}$ & $p$-value \\
\hline BMI & 26.34 & 4.2 & 27.4 & 5.0 & 0.1 \\
\hline $\begin{array}{l}\text { Time seated at work per } \\
\text { day (hours) }\end{array}$ & 7.4 & 1.9 & 6.8 & 1.4 & 0.257 \\
\hline Night shifts per week & 2.4 & 0.7 & 2.6 & 0.9 & 0.62 \\
\hline $\begin{array}{l}\text { Time spent on physical } \\
\text { activity per week (hours) }\end{array}$ & 1.8 & 2.7 & 2.1 & 3.9 & 0.64 \\
\hline Sleep duration (hours) & 6.8 & 1.4 & 7.1 & 1.1 & 0.145 \\
\hline
\end{tabular}

$\mathrm{BMI}$ - body mass index, FIGO - French. Fédération internationale de gynécologie et d'obstétrique, SD - standard deviation

Table 10. Comparison between patients with FIGO stage I or II with patients with stage III or IV

\begin{tabular}{|c|c|c|c|}
\hline \multirow[t]{2}{*}{ Variable } & FIGO stages I and II & FIGO stages III and IV & \multirow[t]{2}{*}{$p$-value } \\
\hline & $\%$ & $\%$ & \\
\hline Not given birth & 44.4 & 55.6 & 1 \\
\hline Not breastfed & 23.8 & 76.2 & $2.03 \times 10^{-3}$ \\
\hline Suffered from painful menstruation & 23.5 & 76.5 & $3.73 \times 10^{-5}$ \\
\hline Not used hormonal contraception & 19.4 & 80.6 & $3.02 \times 10^{-11}$ \\
\hline Had a miscarriage & 36.4 & 63.6 & 0.4 \\
\hline Reported having frequent or recurrent vaginal infections & 11.8 & 88.2 & $4.0 \times 10^{-5}$ \\
\hline Has blood type A & 22.9 & 77.1 & $1.7 \times 10^{-5}$ \\
\hline \multirow[t]{2}{*}{ Variable } & FIGO stages I and II & FIGO stages III and IV & \multirow[t]{2}{*}{$p$-value } \\
\hline & $\%$ & $\%$ & \\
\hline Had sedentary job & 28.6 & 71.4 & $3.3 \times 10^{-3}$ \\
\hline Had night shifts & 18.7 & 81.3 & $1.0 \times 10^{-3}$ \\
\hline Did not exercise regularly & 22.0 & 78.0 & $6.7 \times 10^{-8}$ \\
\hline Sleeping problems & 15.0 & 85.0 & $3.9 \times 10^{-5}$ \\
\hline Did not use analgesics & 20.7 & 79.3 & $9.0 \times 10^{-10}$ \\
\hline
\end{tabular}

FIGO - French. Fédération internationale de gynécologie et d'obstétrique

brought to light more data on these and other potential risk factors for this type of carcinoma.

The correlation between LOC and the risk of ovarian cancer has already been discussed. It was calculated that every year of ovulation increases the risk of the illness by as much as 2.6-6\% [5]. The histological types most closely associated with this factor are serous and endometrioid carcinomas [6]. Nevertheless, there is still a lack of research comparing the number of cycles between women with different FIGO stages. On the basis of the results obtained during the study, it was observed that LOC differed significantly between women interviewed as a control group and patients treated for advanced ovarian cancer $(p=0.0304)$. More research is needed in order to find out whether LOC can also have an influence on the severity of the disease, not only on its occurrence.

Researchers are inconsistent as regards the age at menarche being a risk for ovarian cancer (OC). Some stated that generally a younger age at menarche decreases the odds of developing OC by $15 \%$ [7]. The 
results of the study conducted in our facility do not confirm this calculation. Although the mean age at menarche was similar for both groups (13.4 years in the study group and 13.5 years in the control group), the logistic regression showed that every one year increase in the age at menarche reduces the odds of OC 0.677 times ( $95 \% \mathrm{Cl}: 0.49-0.92 ; p=0.0152$ ). The age at menarche remains one of many variables taken into account when calculating the LOC; therefore it should be suggested to consider this aspect together with others, directly influencing LOC.

Pregnancy is unquestionably one of the most important factors having an impact on preventing ovarian cancer, as well as on the LOC. It was even found to be more beneficial than older age at menarche or younger age at menopause [8]. Troisi et al. reported that women who had given birth had a $30-40 \%$ lower risk of developing OC than nulliparous women and that the mentioned protective effect increases with each subsequent pregnancy [9]. Similar findings were presented in other studies. One calculated the risk of OC decreasing $8 \%$ with every pregnancy [10] and another one calculated a decline of $18 \%, 26 \%, 33 \%$, and $42 \%$ for the first, second, third, and fourth pregnancy respectively [11]. Our results confirm that giving birth has a positive influence on the prevalence of ovarian cancer. The probability of developing $\mathrm{OC}$ for women who had given birth was 0.046 times lower than for nulliparous women (95\% Cl: $0.002-0.523 ; p=0.025)$. $87.3 \%$ of interviewees in the study group had been pregnant at least once, while in the control group it was $97.4 \%$ of women. This difference was statistically significant $(p=0.0456)$. However, the median number of births did not differ between the groups, and for both of them, the result was 2 childbirths per woman. The mean age at the first birth was also similar (23.3 years in the study group and 23.9 years in the control group) and no statistically significant difference or correlation was found regarding this aspect. That is why the subject of pregnancy, perinatal and reproductive factors should be further explored, especially in larger study groups.

The influence of breastfeeding on the occurrence of ovarian cancer appears to be incontrovertible. Multiple studies confirm the reduced risk of this carcinoma among women who have breastfed, but there are no explicit data on how long women should breastfeed in order to decrease their risk of OC effectively. It was discovered that the long duration of all breastfeeding episodes combined, a higher number of breastfeeding episodes, and relatively younger age during the first episode of breastfeeding are additional factors increasing the efficiency of breastfeeding in preventing OC [12]. Luan et al. claim that any breastfeeding history is a preventive factor itself and its efficiency only grows with the extension of the lactation period [13]. A threemonth-long breastfeeding episode was considered to be profitable by two independent studies $[12,14]$ and another one reported that a year-long episode can decrease the risk of ovarian cancer by as much as 35\% in comparison to women who have never breastfed [15]. One hypothesis explaining why breastfeeding is this beneficial states that oxytocin, which is closely associated with breastfeeding, limits the expression of matrix metalloproteinase-2 and vascular endothelial growth factor and this helps to avoid angiogenesis and the growth of cancer cells [16]. The most successful prevention was observed in relation to high-grade serous and endometrioid carcinomas [17]. In this single-center study, statistically significant differences were noted in the duration of women's lactation between the control and study groups $(p=0.034)$ and between the control group and the group of patients classified as FIGO stage III or IV ( $p=0.049)$, which suggests that breastfeeding in fact provides beneficial effects in terms of ovarian cancer prevention. According to the results obtained in logistic regression, every additional month of breastfeeding reduces the risk of the disease 0.94 times, holding all other variables constant $(95 \% \mathrm{Cl}$ : 0.87-0.99; $p=0.0428$ ), which supports available research on the influence of breastfeeding on the risk of ovarian cancer.

Hormonal contraception is considered one of the most successful ways of preventing ovarian cancer. Abundant research has proved that using this type of contraception effectively minimizes the risk of OC $[18,19]$. The protective effect lasts for 25 to 30 years, even if the therapy was only 1-4 years long [20] and was similar regardless of the dose of estrogens and progestins [21]. The difference between the analyzed groups was considerable $-38.2 \%$ of women in the control group reported using oral contraception, whereas only $11.3 \%$ of all oncological patients and $10.5 \%$ of patients in FIGO stage III or IV did so. Both comparisons were statistically significant $\left(p=3.7 \times 10^{-5}\right.$ and $\left.p=1.0 \times 10^{-3}\right)$. The analysis showed that the risk of OC for women who took oral contraception is 0.106 times lower than for the women who did not use this type of contraception (95\% Cl: $0.02-0.41 ; p=1.9 \times 10)$ [3]. These results confirm the importance of hormonal contraception as a preventive tool against OC.

Some research has revealed that painful menstruation could also increase the risk of ovarian cancer. A correlation was observed between moderate and severe pain and epithelial ovarian cancer [22]. According to the results of our study, the patients diagnosed in FIGO stage III or IV stated more frequently than women diagnosed in stages I or II that their periods were, in fact, painful. However, suffering from a painful menstrual period is a common complaint, so this aspect should be investigated on larger groups of patients to assess whether it could have an impact on developing ovarian cancer.

The collected data were also assessed for the prevalence of endometriosis in both the control and study 
groups, as this disease is a well-known risk factor of endometrioid and clear-cell ovarian cancer. Five out of 71 patients were diagnosed with these histological types of carcinomas ( 2 patients with clear-cell carcinoma and 3 patients with endometrioid carcinoma), but none of them reported suffering from endometriosis before being diagnosed with cancer. In the control group, $10.5 \%$ of women $(n=8)$ had endometriosis. These numbers were too small to conduct any conclusive statistics and provide reasonable data; however, the subject of endometriosis and ovarian cancer should be further explored.

Blood type can have a direct influence on the risk of cancer, as it has been proven for pancreatic and gastric cancer. Some research has shown that women with blood type $A$ are more likely to develop ovarian cancer $[23,24]$, whereas those with blood type 0 have a lower risk of this kind of cancer [23]. According to Björkholm et al., this blood type increases the risk of the serous type of ovarian cancer by $15 \%$ [23]. A possible explanation for this particular connection was presented by Henderson et al., who claimed that ovarian cancer cells release the Forssman antigen, which is very similar to the determinant of blood type A antigen [25]. This way people who have anti-A antibodies are less subject to developing ovarian cancer because these antibodies tend to damage already existing cancerous cells and therefore prevent the growth of the neoplasm. In the study conducted in our facility, the women diagnosed at FIGO stage III or IV had blood type A more often than women diagnosed in FIGO stage I or II $\left(p=1.7 \times 10^{-5}\right)$. There is no research yet considering the potential influence of blood type on the stage of ovarian cancer on larger study groups. The comparison between the distribution of blood types in the study group, the control group, and in Polish society brought results that would confirm the mentioned studies. Blood type A was present more often in patients with ovarian cancer than in the control group and Polish society, and blood type 0 was present more often among women in the control group, as well as among Polish society. However, this outcome was not statistically significant and should be confirmed in larger study groups, as noted above.

As it is commonly known, obesity is a risk factor for many malignancies. It has been estimated that in Europe as many as $5 \%$ of all malignancies may be related to being overweight [26]. Higher levels of IGF-1, insulin, or leptin may promote the growth of cancer cells. Adipose tissue produces pro-inflammatory factors such as TNF- $\alpha$, IL-6 [27] or C-reactive protein [28] that, according to the theory of constant inflammation [3], may contribute to the process of carcinogenesis in ovaries. Many studies have already proven that obesity is a risk factor for ovarian cancer occurrence. It is also associated with a poorer prognosis [29]. Increased risk has been observed when obesity occurred up to 5 years before the diagnosis, in youth [30] and also during the perimenopausal period [31]. Moreover, the diet itself affects the time of menarche and menopause. A high energy diet promotes early menarche and late menopause; therefore, it increases LOC and hence the risk of ovarian cancer [32]. The mean $\mathrm{BMI}$ value of the study group was 26.2 and of the control group 27.4. Both of these values exceed the norm and correspond to being overweight. However, only $18.3 \%$ of women in the study group were obese (vs. $27.6 \%$ of women in the control group). Therefore, a 5 -year follow-up must be performed in order to evaluate the impact of obesity on the survival of these women.

It has been proven that physical activity reduces constant inflammation [3]. Moreover, regular, heavy workouts can inhibit ovulation, which was observed in athletes [33]. Therefore, physical activity decreases the number of $\mathrm{LOC}$ and the risk of ovarian cancer. According to the analysis conducted by Minlikeeva et al. [34], all three factors together - lack of any physical exercise, obesity, and smoking - have a negative effect on the survival of patients suffering from ovarian cancer. Only $29.6 \%$ of patients in the study group reported performing physical activity regularly, in comparison to $35.5 \%$ of women in the control group. Women who did not exercise more often had advanced cancer at FIGO stage III or IV than at stage I or II $\left(p=6.7 \times 10^{-8}\right)$. These data prove the effect of lifestyle-related factors on the prevalence of ovarian cancer. It is, therefore, essential to motivate patients to exercise and live a healthy lifestyle in order to prevent the occurrence of ovarian cancer.

Working night shifts has already been classified as a possible carcinogenic factor. It has been suggested that melatonin, produced at night time and suppressed by light, may affect ovarian function [35]. $22.5 \%$ of women in the study group reported having worked night shifts in comparison to $15.8 \%$ in the control group. Among women who reported ever working night shifts, more often these were women with FIGO stage III or IV than I or II $\left(p=1.0 \times 10^{-3}\right)$. Published research provided information about 1.24 times greater risk among women who had worked night shifts in comparison to women who had never worked night shifts. However, after performing logistic regression analysis on the data obtained from this study, the OR of developing ovarian cancer was estimated as 5.46 times greater than for women who had not worked night shifts, holding all other variables constant $(\mathrm{OR}=5.46 ; 95 \% \mathrm{Cl}$ : $1.52-22.62$; $p=0.0128$ ). Therefore, both of these results are consistent and must be taken into consideration, especially due to the character of medical professions.

Having a sedentary job is extremely common, especially during the COVID-19 pandemic. There are no consistent data about the impact of sedentary jobs on ovarian cancer occurrence. This factor must be analyzed along with obesity and lack of physical activity, as they are closely connected. Exercise should be performed 
in leisure time in order to prevent both cardiovascular diseases and malignancies. Surprisingly, women in the control group more often had sedentary jobs than women with advanced cancer $-55.3 \%$ vs. $35.1 \%$ respectively $(p=0.033)$. However, patients who had sedentary work more often had advanced cancer (at FIGO stage III or IV) rather than at stage I or II $\left(p=3.3 \times 10^{-3}\right)$. It is possible that women in the control group were more active during their leisure time than the study group. Another reason for this may be that night shifts, which are more common in the study group, increase the risk more than sedentary jobs. Considering the results presented above, definitely more emphasis should be put on the importance of a healthy lifestyle and regular exercise.

Sleeping disorders and chronic fatigue are associated with the poor quality of life of women suffering from ovarian cancer. However, there are no consistent data about the effect of sleeping disorders and lack of a proper amount of sleep on the occurrence of ovarian cancer. Recent research suggested that there is no correlation between sleep and ovarian cancer occurrence after menopause. Nevertheless, restful sleep quality is associated with a lower risk of invasive serous ovarian cancer, whereas insomnia is associated with a higher one [36]. 28.2\% of patients in the study group reported having sleep disorders prior to diagnosis (vs. $42.1 \%$ in the control group). However, these women were more often diagnosed with advanced cancer (at FIGO stage III or IV) than at stage I or II $\left(p=3.9 \times 10^{-5}\right)$. Moreover, the median duration of sleep of women with cancer at FIGO stage IV was only 5 hours. It was significantly less than in the case of other stages $\left(p=2.6 \times 10^{-3}\right)$. Based on this result, it can be assumed that sleep duration may have an impact on ovarian cancer occurrence and more emphasis should be put on getting a proper amount of rest per day.

Analgesic drugs, commonly known as painkillers, are frequently used; therefore, their possible impact on carcinogenesis has been evaluated in order to prove their long-term safety. The pathogenesis of ovarian cancer may be associated with constant inflammation [3]. Non-steroidal anti-inflammatory drugs (NSAIDs), especially aspirin, have been proven to reduce the ovarian cancer risk by $44 \%$ in the case of aspirin (OR $=0.56)$ and $26 \%(O R=0.74)$ in the case of non-aspirin NSAIDs [37]. The impact of another common drug, paracetamol, on ovarian cancer occurrence was analyzed in a Danish study [38]. As well as NSAIDs, it has been proven to reduce the incidence of ovarian cancer $(\mathrm{OR}=0.82)$. The odds ratio continued to decrease in the case of long-term (above 10 years) and high-intensity use $(\mathrm{OR}=0.45) .16 .9 \%$ of the entire study group and $17.5 \%$ of women with advanced cancer at FIGO stages III and IV reported using painkillers at least once a week in comparison to $28.9 \%$ of women in the control group. Women who did not use analgesics more often had cancer at FIGO stage III or IV than at stage I or II $\left(p=9.0 \times 10^{-10}\right)$.
Therefore, the usage of aspirin as prophylaxis seems not only beneficial in terms of cardiovascular diseases but also gynecological ones and requires further research.

\section{Conclusions}

Ovarian cancer is still one of the most puzzling gynecological cancers. As there is no effective screening available and the symptoms are not visible and specific enough, this disease is diagnosed far too often in advanced stages, which equates to limited treatment possibilities. This study confirms well-known and openly discussed gynecological risk factors of ovarian cancer, such as nulliparity, lack of breastfeeding, lack of hormonal contraception use, and an increased number of LOC, as well as pointing out the importance of lifestyle as a complex but potentially very significant risk factor for this malignancy. Medicines taken throughout life, sleep quality, profession, and its character, and work shifts at night are other aspects that should be considered relevant in the context of the risk of ovarian cancer. Some of the outcomes presented in this study suggest that there might be a direct connection between the occurrence of the factors and the stage of the disease at diagnosis. Acknowledging and gaining more insight on the subject could reduce the prevalence and mortality rate of this carcinoma. Being aware of the limitations of this study, such as the relatively small number of patients recruited, the authors suggest that the topic of gynecological history and lifestyle as a source of risk factors of ovarian cancer should be further explored, especially in multiple centers and in larger study and control groups.

\section{Disclosure}

The authors report no conflict of interest.

\section{References}

1. Wojciechowska U, Didkowska J. Zachorowania i zgony na nowotwory złośliwe w Polsce. Krajowy Rejestr Nowotworów, Narodowy Instytut Onkologii im. Marii Skłodowskiej-Curie - Państwowy Instytut Badawczy. Available from: http://onkologia.org.pl/raporty/ dostęp z dnia 16.03.2021

2. Fathalla MF. Incessant ovulation and ovarian cancer - a hypothesis revisited. Facts Views Vis Obgyn 2013; 5: 292-297.

3. Ness RB, Cottreau C. Possible role of ovarian epithelial inflammation in ovarian cancer. J Natl Cancer Inst 1999; 91: 1459-1467.

4. Matulonis UA, Sood AK, Fallowfield L, Howitt BE, Sehouli J, Karlan BY. Ovarian cancer. Nat Rev Dis Primers 2016; 2: 16061.

5. Pelucchi C, Galeone C, Talamini R, et al. Lifetime ovulatory cycles and ovarian cancer risk in 2 Italian case-control studies. Am J Obstet Gynecol 2007; 196: 83.e1-7.

6. Peres LC, Moorman PG, Alberg AJ, et al. Lifetime number of ovulatory cycles and epithelial ovarian cancer risk in African American women. Cancer Causes Control 2017; 28: 405-414.

7. Gong T-T, Wu Q-J, Vogtmann E, Lin B, Wang Y-L. Age at menarche and risk of ovarian cancer: a meta-analysis of epidemiological studies. Int J Cancer 2013; 132: 2894-2900. 
8. Negri E, Franceschi S, Tzonou A, et al. Pooled analysis of 3 European case-control studies: I, reproductive factors and risk of epithelial ovarian cancer. Int J Cancer 1991; 49: 50-56.

9. Troisi R, Bjørge T, Gissler M, et al. The role of pregnancy, perinatal factors and hormones in maternal cancer risk: a review of the evidence. J Intern Med 2018; 283: 430-445.

10. Tsilidis KK, Allen NE, Key TJ, et al. Oral contraceptive use and reproduc tive factors and risk of ovarian cancer in the European Prospective Investigation into cancer and nutrition. Br J Cancer 2011; 105: 1436-1442.

11. Wentzensen N, Poole EM, Trabert B, et al. Ovarian cancer risk factors by histologic subtype: an analysis from the ovarian cancer cohort consortium. J Clin Oncol 2016; 34: 2888-2898.

12. Modugno F, Goughnour SL, Wallack D, et al. Breastfeeding factors and risk of epithelial ovarian cancer. Gynecol Oncol 2019; 153: 116-122.

13. Luan N-N, Wu Q-J, Gong T-T, Vogtmann E, Wang Y-L, Lin B. Breastfeeding and ovarian cancer risk: a meta-analysis of epidemiologic studies. Am J Clin Nutr 2013; 98: 1020-1031.

14. Babic A, Sasamoto N, Rosner BA, et al. Association between breastfeeding and ovarian cancer risk. JAMA Oncol 2020; 6: e200421.

15. Chowdhury R, Sinha B, Sankar MJ, et al. Breastfeeding and maternal health outcomes: a systematic review and meta-analysis. Acta Paediatrica 2015; 104: 96-113.

16. Ji H, Liu N, Yin Y, et al. Oxytocin inhibits ovarian cancer metastasis by repressing the expression of MMP-2 and VEGF. J Cancer 2018; 9: $1379-1384$

17. Jordan SJ, Cushing-Haugen KL, Wicklund KG, Doherty JA, Rossing MA. Breast-feeding and risk of epithelial ovarian cancer. Cancer Causes Control 2012; 23: 919-927.

18. Riman T, Dickman PW, Nilsson S, et al. Risk factors for invasive epithelial ovarian cancer: results from a Swedish case-control study. Am J Epidemiol 2002; 156: 363-373.

19. Beral V, Doll R, Hermon C, et al. Ovarian cancer and oral contraceptives: collaborative reanalysis of data from 45 epidemiological studies including 23,257 women with ovarian cancer and 87,303 controls. Lancet 2008; 371: 303-314.

20. Ness RB, Grisso JA, Klapper J, et al. Risk of ovarian cancer in relation to estrogen and progestin dose and use characteristics of oral contraceptives. SHARE Study Group. Steroid Hormones and Reproductions. Am J Epidemiol 2000; 152: 233-241.

21. Rosenblatt KA, Thomas DB, Noonan EA, et al. High-dose and low-dose combined oral contraceptives: protection against epithelial ovarian cancer and the length of the protective effect. Eur J Cancer 1992; 28A: 1872-1876.

22. Babic, A, Cramer DW, Titus LJ, Tworoger SS, Terry KL. Menstrual pain and epithelial ovarian cancer risk. Cancer Causes Control 2014; 25: 1725-1731.

23. Björkholm E. Blood group distribution in women with ovarian cancer. Int J Epidemiol 1984; 13: 15-17.

24. Cozzi GD, Levinson RT, Toole Het al. Blood type, ABO genetic variants, and ovarian cancer survival. PLoS One 2017; 12: e0175119.

25. Henderson J, Seagroatt V, Goldacre M. Ovarian cancer and ABO blood groups. J Epidemiol Community Health 1993; 47: 287-289.

26. Bergström A, Pisani P, Tenet V, Wolk A, Adami HO. Overweight as an avoidable cause of cancer in Europe. Int J Cancer 2001; 91: 421-430.

27. Calle EE, Kaaks R. Overweight, obesity and cancer: epidemiological evidence and proposed mechanisms. Nat Rev Cancer 2004; 4: 579-591.

28. Rexrode KM, Pradhan A, Manson JE, Buring JE, Ridker PM. Relationship of total and abdominal adiposity with CRP and IL-6 in women. Ann Epidemiol 2003; 13: 674-682.

29. Schouten LJ, Goldbohm RA, van den Brandt PA. Height, weight, weight change, and ovarian cancer risk in the Netherlands cohort study on diet and cancer. Am J Epidemiol 2003; 157: 424-433.

30. Bae HS, Kim HJ, Hong JH, Lee JK, Lee NW, Song JY. Obesity and epithelial ovarian cancer survival: a systematic review and meta-analysis. J Ovarian Res 2014; 7: 41

31. Liu Z, Zhang TT, Zhao JJ, et al. The association between overweight, obesity and ovarian cancer: a meta-analysis. Jpn J Clin Oncol 2015; 45: 1107-1115.

32. Wiseman M, Cannon G. Food, nutrition, physical activity and the prevention of cancer: a global perspective, Washington, DC, USA, 2007.

33. De Souza MJ. Menstrual disturbances in athletes: a focus on luteal phase defects. Med Sci Sports Exerc 2003; 35: 1553-1563.
34. Minlikeeva AN, Cannioto R, Jensen A, et al. Joint exposure to smoking, excessive weight, and physical inactivity and survival of ovarian cance patients, evidence from the Ovarian Cancer Association Consortium. Cancer Causes Control 2019; 30: 537-547.

35. Bhatti P, Cushing-Haugen KL, Wicklund KG, Doherty JA, Rossing MA Nightshift work and risk of ovarian cancer. Occup Environ Med 2013; 70: 231-237

36. Liang $X$, Harris HR, Hendryx $M$, et al. Sleep characteristics and risk of ovarian cancer among postmenopausal women. Cancer Prev Res (Phila) 2021; 14: 55-64.

37. Peres LC, Camacho F, Abbott SE, et al. Analgesic medication use and risk of epithelial ovarian cancer in African American women. Br J Cancer 2016; 114: 819-825.

38. Baandrup L, Friis S, Dehlendorff C, Andersen K, Olsen J, Kjaer S. Prescription use of paracetamol and risk for ovarian cancer in Denmark. JNCI 2014; 106: dju111. 